\title{
Nuclear receptors and AMPK: can exercise mimetics cure diabetes?
}

\author{
Christopher E Wall1,2, Ruth T Yu', Anne R Atkins', Michael Downes' \\ and Ronald M Evans 1,3
}

${ }^{1}$ Gene Expression Laboratory, Salk Institute, La Jolla, California, USA 2Biomedical Sciences Graduate Program, UC San Diego, La Jolla, California, USA

${ }^{3}$ Howard Hughes Medical Institute, Salk Institute, La Jolla, California, USA
Correspondence should be addressed to R M Evans

Email

evans@salk.edu

\begin{abstract}
Endurance exercise can lead to systemic improvements in insulin sensitivity and metabolic homeostasis, and is an effective approach to combat metabolic diseases. Pharmacological compounds that recapitulate the beneficial effects of exercise, also known as 'exercise mimetics', have the potential to improve disease symptoms of metabolic syndrome. These drugs, which can increase energy expenditure, suppress hepatic gluconeogenesis, and induce insulin sensitization, have accordingly been highly scrutinized for their utility in treating metabolic diseases including diabetes. Nevertheless, the identity of an efficacious exercise mimetic still remains elusive. In this review, we highlight several nuclear receptors and cofactors that are putative molecular targets for exercise mimetics, and review recent studies that provide advancements in our mechanistic understanding of how exercise mimetics exert their beneficial effects. We also discuss evidence from clinical trials using these compounds in human subjects to evaluate their efficacy in treating diabetes.
\end{abstract}

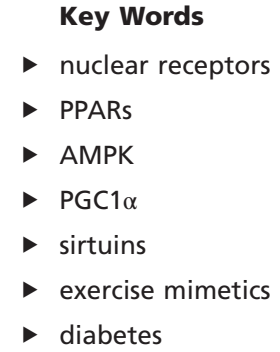

Journal of Molecular Endocrinology (2016) 57, R49-R58

\section{Introduction}

Lifestyle interventions such as improving diet and exercise habits can effectively combat many disease symptoms associated with metabolic syndrome, including obesity, hyperglycemia, insulin resistance, inflammation, hypercholesterolemia, and diabetes (Knowler et al. 2002, Shin et al. 2013). Even a small increase in daily physical activity can improve muscle fitness, promote resistance to diet-induced obesity, and reduce systemic inflammation (Warburton etal.2006). Although the mechanisms through which exercise improves the symptoms of metabolic diseases are incompletely understood, adaptive changes in oxidative metabolism and mitochondrial function of skeletal muscle are believed to play a significant role (Fan et al. 2013). Endurance training in skeletal muscle can be mechanistically linked to activation of an AMP-sensitive gene expression program coordinated by 5'-adenosine monophosphate-activated protein kinase (AMPK) and the nuclear receptor peroxisome proliferator-activated receptor delta (PPARס) (Narkar et al. 2008). Two drugs that target these pathways, the AMP-analog 5-amino- $1-\beta$-Dribofuranosyl-imidazole-4-carboxamide (AICAR) and the PPARS ligand GW501516, can greatly improve exercise performance in mice without training (Narkar et al. 2008). Subsequently, other drugs with exercise-mimetic effects have been identified as potential therapeutic avenues for metabolic diseases.

In this review, we discuss recent findings that address the efficacy of targeting AMPK and/or nuclear receptorcontrolled pathways to mimic some of the benefits of exercise, and whether compounds that modulate AMPK http://jme.endocrinology-journals.org DOI: 10.1530/JME-16-0073
๑ 2016 Society for Endocrinology Printed in Great Britain 
and nuclear receptor activity might be useful for treating metabolic diseases such as type 2 diabetes (T2D). How might one specific exercise mimetic be used as a therapy for a complex disease such as T2D? One apparent mechanism is through the induction of glucose uptake in tissues such as skeletal muscle and fat, which removes excess glucose from circulation. As skeletal muscle is one of the major sites responsible for glucose clearance and utilization in the body, exercise-induced glucose uptake in skeletal muscle is a convenient and straightforward method to lower blood glucose level and improve insulin sensitivity (Baron et al. 1988). Hepatic gluconeogenesis is another major contributor for hyperglycemia, and interventions that inhibit gluconeogenesis could accordingly be antidiabetic (Magnusson et al. 1992). In addition, circulating fatty acids are negatively associated with insulin-dependent glucose uptake, providing one more target to develop antidiabetic therapies (Boden \& Shulman 2002). Exercise is able to reduce hyperglycemia, suppress de novo glucose synthesis, and increase the uptake and metabolism of fatty acids, removing them from circulation. Accordingly, when evaluating exercise mimetics as potential therapies for $\mathrm{T} 2 \mathrm{D}$, we discuss three separate therapeutic strategies: reducing plasma glucose levels, suppressing gluconeogenesis, and sequestering/ oxidizing fatty acids that promote insulin resistance. The safety, specificity, and strategies for therapeutic delivery for each exercise mimetic will also be considered.

\section{PPAR8: using GW501516 to promote oxidative metabolism in muscle}

The PPAR family of nuclear receptors has long been appreciated for its role in regulating lipid metabolism and energetic homeostasis by their direct control of metabolic gene expression (Schoonjans et al. 1996). Mechanistically, PPARs operate as ligand-inducible transcription factors constitutively bound to consensus response elements on chromatin in a heterodimer with the retinoid X receptors (RXRs) (Barish et al. 2006). PPARס was one of the first nuclear receptors to garner attention as a potential mediator of exercise given its importance in mitochondrial energy metabolism in skeletal muscle (Barish et al. 2006). Transgenic mice overexpressing a constitutively active form of PPAR $\delta$ were shown to have a pro-endurance oxidative fiber-type shift with induced mitochondrial biogenesis in skeletal muscle. Therefore, PPARס ligands naturally surfaced as putative exercise mimetics (Wang et al. 2003). Originally developed as a drug to treat hyperlipidemia (Oliver et al. 2001), the PPAR8-specific ligand GW501516 has been studied and reviewed extensively as an exercise mimetic since it was first demonstrated to synergistically promote endurance with exercise training in mice (Dressel et al. 2003, Narkar et al. 2008). At present, GW501516 has demonstrated some promise in a handful of phase 1 and phase 2 clinical trials for metabolic disorders such as hypercholesterolemia and dyslipidemia with no known side effects in humans, but has yet to move past this stage of study (Olson et al. 2012, Ooi et al. 2011). However, GW501516 was almost immediately and widely used as a doping agent by athletes after its discovery as a potential exercise mimetic, and has subsequently been banned by the World AntiDoping Agency (Thevis et al. 2009). This fact is somewhat disconcerting considering that GW501516, in a similar manner to compounds that activate PPAR $\alpha$, has been reported to promote carcinogenesis in some animal models (Wang et al. 2006). GW501516 has also been linked to a decrease in bone density in ovariectomized rats, similar to side effects observed with PPAR $\gamma$ agonists (Mosti et al. 2014). In addition, GW501516 can potentiate liver fibrosis in response to CCl4-induced injury through a pro-proliferative mechanism (Kostadinova et al. 2012). Despite the known side effects, GW501516 still presents as an attractive antidiabetic compound given its profound effects on promoting oxidative metabolism. While oral administration of GW501516 might not be desirable due to its aforementioned side effects, targeted administration of GW501516 to muscle or elsewhere could provide an interesting alternative. A recent example of this strategy used topical application of polymer-encapsulated GW501516 to successfully promote healing of diabetic wounds by reducing oxidative stress in the wound microenvironment (Wang et al. 2015). Future studies, including additional animal studies carefully focusing on the tissue-specific effects of GW501516, would be necessary to establish the utility of this compound as a potential efficacious treatment for diabetes. Alternatively, the development of other PPAR $\delta$ ligands with more exercise-specific effects could circumvent the undesirable side effects of GW501516.

\section{PPAR $\alpha$ : targeting the liver to promote metabolic fitness through FGF21}

In a way similar to PPARS, PPAR $\alpha$ also regulates the expression of genes that control oxidative metabolism and lipid homeostasis. PPAR $\alpha$ has several known endogenous ligands, most of which are fatty acids that can originate from dietary sources, lipolysis of lipid storage in adipose

Published by Bioscientifica Ltd. 
tissues, or de novo lipogenesis (Dreyer et al. 1993). While PPARS is responsible for regulating its target genes most critically in skeletal muscle, PPAR $\alpha$ functions in the liver to adapt to fluctuations in metabolic homeostasis (Contreras et al. 2013). For example, caloric restriction can result in lipolysis of white adipose tissue, liberating fatty acids that activate PPAR $\alpha$ in the liver. Consequently, ligandactivated PPAR $\alpha$ can induce the expression of its endocrine hormone-target genes that regulate adaptive changes in other tissues (Kersten et al. 1999). As this fasting response closely resembles metabolic improvements observed with exercise training, could compounds that target PPAR $\alpha$ be used as exercise mimetics to treat diabetes?

Given the strong link between PPAR $\alpha$ activity and metabolic fitness, recent research efforts have also focused on PPAR $\alpha$-target genes that exert its beneficial effects. One such candidate is the endocrine hormone fibroblast growth factor 21 (FGF21), which is produced and secreted by the liver in response to metabolic stress such as fasting (Inagaki et al. 2007, Lundasen et al. 2007). Acute bouts of exercise are able to induce hepatic FGF21 expression and increase circulating FGF21 levels as well (Cuevas-Ramos et al. 2012). Peripherally, FGF21 promotes a starvation-like state, and can stimulate glucose uptake and fatty acid oxidation in metabolic tissues such as muscle and fat (Potthoff et al. 2009, Mashili et al. 2011). Transgenic mice overexpressing $\mathrm{Fg} f 21$ in the liver as well as mice administered with supra-physiologic doses of FGF21 have significantly improved insulin sensitivity and resistance to metabolic syndrome (Kharitonenkov \& Larsen 2011, Zhang et al. 2012b). Accordingly, FGF21 has been pursued as a potential therapy for metabolic diseases, but off-target effects such as those resulting in bone loss (Wei et al. 2012) have presented an obstacle. Current research efforts are instead directed toward the development of modified FGF21 variants that lack deleterious side effects. Recent studies have used these variants to improve metabolic homeostasis in diabetic monkeys as well as in a clinical trial involving obese human patients (Adams et al. 2013, Gaich et al. 2013). Strategies aimed at inducing FGF21 natively through a physiological metabolic stress while simultaneously circumventing the undesirable side effects of PPAR $\alpha$ activation could also be potentially effective antidiabetic therapies (Wu et al. 2011, Bookout et al. 2013).

\section{PPAR $\gamma$ : new mechanisms for generating insulin-sensitizing adipokines}

PPAR $\gamma$ has long been a target for developing therapies for metabolic diseases, and the PPAR $\gamma$-activating thiazolidinedione (TZD) class of drugs have been prolific antidiabetics since the early 1990s (Spiegelman 1998). PPAR $\gamma$ is essential for the development of adipose tissue, and regulates the expression of lipid metabolism genes as well as adipokines with critical metabolic functions such as adiponectin (Berger et al. 2005). Indeed, energetic stressors such as exercise and fasting can modulate PPAR $\gamma$ activity and the expression of its target genes in adipose tissue, highlighting PPAR $\gamma$ as a potential target for developing novel exercise mimetics (Vidal-Puig et al. 1996, Butcher et al. 2008). Even though the efficacy of PPAR $\gamma$ ligands in treating T2D has been firmly established, the precise mechanisms through which they function are still under investigation. Activation of PPAR $\gamma$ by TZDs is generally believed to enhance adipocyte development and lipid handling which results in increased absorption of circulating fatty acids into adipose tissue and promotes insulin resistance (Lehrke \& Lazar 2005). Recently, TZDs were found to inhibit phosphorylation on the S273 residue of PPAR $\gamma$ by cyclin-dependent kinase 5 (CDK5), causing a dysregulated expression pattern of PPAR $\gamma$-target genes in white adipose tissue indicative of obesity (Choi et al. 2010). The phosphorylated S273 can be bound by thyroid hormone receptor-associated protein 3 (THRAP3), which is essential for mediating PPAR $\gamma$ activity in obesogenic states (Choi et al. 2014a). This paradigm has already been explored as a potential therapeutic target for T2D using the nonagonist PPAR $\gamma$ ligand UHC1, which exclusively prevents the phosphorylation of S273 on PPAR $\gamma$. As a result, UHC1 treatment not only improved insulin sensitivity but also reduced diet-induced obesity, which is quite different from the TZDs (Choi et al. 2014b). In addition to providing mechanistic insight into how TZDs and PPAR $\gamma$ are involved in the progression of diabetes, these studies also implicate THRAP3 and CDK5 as prospective antidiabetic targets as well.

In addition to its role in sequestering lipids that promote insulin resistance, PPAR $\gamma$ also controls the expression of key adipokines that regulate metabolic homeostasis. For example, adiponectin, a PPAR $\gamma$-target gene produced and released from white adipose tissue, is able to suppress hepatic gluconeogenesis, activate glucose uptake in peripheral tissues, increase lipid catabolism, and promote weight loss (Yamauchi et al. 2001). Interestingly, adipose-derived adiponectin was recently shown to relay the FGF21-mediated systemic improvements in metabolic fitness, proposing a coordinated mechanism by which activation of PPAR $\alpha$ in liver and PPAR $\delta$ in fat produce an exercise-like metabolic improvement (Holland et al. 2013, Lin et al. 2013). Another adipokine, fibroblast

Published by Bioscientifica Ltd. 
growth factor 1 (FGF1), has also been identified as an adipose-specific PPARס-target gene important for adipocyte remodeling and differentiation (Jonker et al. 2012). Accordingly, Fof1-knockout mice are unable to maintain the plasticity of adipose tissues when challenged with a high-fat dietary stress (Jonker et al. 2012). Although physiological FGF1 functions predominantly in an autocrine manner due to its high affinity for cell surface heparan sulfate proteoglycans, ectopic injection of recombinant FGF1 rapidly lowered glucose levels by $50 \%$, suppressed hepatic glucose production, and improved insulin sensitivity in obese diabetic mice, with the effects sustained for approximately 2 weeks (Suh et al. 2014). Such metabolic effects of FGF1 are independent of its mitogenic growth hormone-like effects since a nonmitogenic form of FGF1 can still induce similar effects (Suh et al. 2014). Comprehensively, these studies propose the therapeutic use of PPARס-regulated adipokines to improve systemic metabolic homeostasis.

\section{PGC1 1 : promoting thermogenic metabolism in brown and beige fat}

PPARS is also essential for the development and function of brown adipose tissue (BAT), a mitochondrially dense and highly metabolic fat tissue responsible for adaptive thermogenesis (Cannon \& Nedergaard 2004). When stimulated by cold challenge and adrenergic signaling, BAT can rapidly uptake and burn glucose to generate heat through uncoupled mitochondrial oxidative phosphorylation. Induction of thermogenesis in BAT is directly mediated by PPAR gamma coactivator 1 alpha (PGC1 $\alpha$ ) (Wu et al. 1999). PGC1 $\alpha$ is also highly induced in skeletal muscle by exercise, where it activates nuclear receptors such as the PPARs and estrogen-related receptors (ERRs) to induce genes that are involved in mitochondrial energy expenditure, fatty acid oxidation, and glucose uptake (Baar et al. 2002, Finck \& Kelly 2006). Therefore, PGC1 $\alpha$ has been an attractive target for antidiabetic therapies aiming to improve metabolic fitness by inducing energy expenditure, and has been extensively studied and reviewed as a putative target for exercise mimetics in fat and muscle (Lin et al. 2005).

In the last few years, several studies have highlighted the potential to use PGC1 $\alpha$-dependent pathways to 'brown' subcutaneous white fat pads to create 'beige' fat that expresses genes specific for brown fat function and has increased mitochondrial energy expenditure and increased uptake of glucose and lipids (Harms \& Seale 2013). Mechanistically, how can browning of white fat be achieved? TZD treatment has been linked to browning, and TZD binding to PPAR $\gamma$ facilitates the direct interaction between PPAR $\gamma$ and the deacetylase sirtuin 1 (SIRT1). When deacetylated by SIRT1, PPAR $\gamma$ induces the expression of genes that mediate thermogenesis in white fat (Qiang et al. 2012). Accordingly, a SIRT1 gain-of-function model resulted in a similar browning effect as observed in TZD treatment, which significantly improved insulin sensitivity (Qiang et al. 2012). Browning has also been recently associated with inflammation, with macrophages recruited to white fat during cold challenge facilitating its transition to the beige state (Qiu et al. 2014). IL4 treatment alone was also sufficient to increase the amount of beige fat and subsequently reduce the symptoms of obesity in mice (Qiu et al. 2014). Metabolic endocrine hormones, including FGF21, have also been closely associated with browning in mice and humans, but conflicting evidence exists as to their actual specific contribution to the development of beige fat (Lee et al. 2014). One such hormone that has been hotly contested recently in the browning field is irisin, a myokine that is secreted from skeletal muscle by the cleavage of fibronectin type III domaincontaining protein 5 (FNDC5). The expression of FNDC5 and secretion of irisin are induced by exercise in skeletal muscle in a PGC1 $\alpha$-dependent manner. In mouse, irisin acts on white adipose tissues and turns on its browning program, which induces energy expenditure and protects against diet-induced obesity and diabetes (Bostrom et al. 2012). Given these findings, recombinant irisin certainly seems like an attractive exercise-mimetic candidate useful for the treatment of T2D. However, mixed findings have been recently published regarding the relevance of irisin to browning in humans. For example, irisin levels in circulation as well as in muscle and fat have been inversely correlated with obesity in human subjects, and human white adipose cell lines have yet to show sensitivity to irisin-mediated browning (Elsen et al. 2014). In addition, emerging evidence suggests that irisin may originate from adipose tissue in addition to muscle (Crujeiras et al. 2014). Further investigation into the molecular mechanisms that govern browning in human and animal models will be required to determine if this process can be efficaciously targeted by exercise mimetics.

\section{AMPK: targeting the central regulator of energy homeostasis}

Long considered to be at the nexus of metabolic signaling pathways, AMP-activated protein kinase (AMPK) relays fluctuations in intracellular energy supply to functional

Published by Bioscientifica Ltd 
cellular energetics by simultaneously activating catabolic and repressing anabolic processes (Hardie 2011). Mechanistically, AMP interacts with AMPK's gamma subunit, facilitating an activating phosphorylation of the alpha subunit by upstream regulatory kinases such as LKB1. This allows AMPK to phosphorylate its downstream targets, many of which are key participants or regulators of energy metabolism pathways including nuclear receptor cofactors such as PGC1 $\alpha$ (Shaw et al. 2005, Jager et al. 2007, Gwinn et al. 2008). Accumulating evidence has established a 'global' role for AMPK in relaying energetic stress to physiological changes from a wide array of environmental stimuli such as caloric restriction, exercise, and disease conditions such as T2D (Narkar et al. 2008, Canto \& Auwerx 2009). As such, pharmacological modulation of AMPK activity has developed into an attractive and widely studied therapeutic avenue for metabolic disorders.

To date, several AMPK-targeted exercise-mimetic compounds have been designed and exhaustively tested with this aim in mind. At the forefront is AICAR, an adenosine analog whose intracellular metabolite directly interacts with and activates AMPK (Sullivan et al. 1994). AICAR has been shown to induce glucose uptake in skeletal muscle via AMPK-dependent stimulation of the translocation of the cellular glucose transporter GLUT4 onto cell membranes (Russell et al. 1999). When administered to sedentary mice, AICAR alone can significantly enhance exercise performance without training through facilitating an oxidative fiber-type switch and mitochondrial biogenesis in skeletal muscle (Narkar et al. 2008). More recently, AICAR has also been used to recapitulate exercise's mood-improving effects while simultaneously improving insulin sensitivity in a mouse model of depression and diet-induced obesity (Liu et al. 2014). Despite the known benefits, AICAR has yet to demonstrate its antidiabetic efficacy in humans, due to it being rapidly metabolized once administered, and its marginal oral activity (Musi \& Goodyear 2002). In addition, AICAR administration in humans has been linked to lactic acidosis, an undesirable side effect which has shelved other antidiabetic compounds in the past (Musi \& Goodyear 2002). Even though these issues have not been resolved to date, AICAR still has potential and continues to be pursued as a possible antidiabetic agent.

Metformin, a drug of the biguanide class known to function in an AMPK-dependent manner, is one of the most widely used antidiabetic drugs on the market today (Zhou et al. 2001, Knowler et al. 2002). Despite the broad usage of metformin to this end due to its efficacious, if transient, ability to improve insulin sensitivity, the precise mechanism by which metformin exerts its effects is imperfectly understood (Luengo et al. 2014). One proposed mechanism for metformin is as an inhibitor of the mitochondrial electron transport chain (ETC): by interacting with the ETC directly, metformin disrupts the normal process of cellular ATP generation, creating cellular energy deficit (Andrzejewski et al. 2014), which in turn induces mitochondrial energy metabolism by activating AMPK and its subsequent downstream targets (Zhou et al. 2001). Recently metformin has also been linked to bile acid homeostasis in liver through its activation of AMPK. Upon activation, AMPK directly phosphorylates and activates the nuclear receptor farnesoid $\mathrm{X}$ receptor (FXR) in the liver, promoting metabolic homeostasis (Lien et al. 2014). Interestingly, structural studies have also suggested that metformin might interact directly with AMPK's gamma subunit in a manner similar to AMP (Zhang et al. 2012a). Recent evidence, however, has proposed alternative mechanisms for metformin's action. For example, metformin was found to directly inhibit the mitochondrial enzyme glycerophosphate dehydrogenase, which is involved in the gluconeogenic pathway in liver (Madiraju et al. 2014). This inhibition disrupted the redox-sensitive lactate-to-pyruvate ratio, resulting in suppressed hepatic gluconeogenesis (Madiraju et al. 2014). Similar phenotypes were also observed in mice deficient for glycerophosphate dehydrogenase (Madiraju et al. 2014). These findings are supported by independent studies demonstrating the ability of metformin to inhibit hepatic gluconeogenesis in an AMPK-independent manner (Foretz et al. 2010). While precise mechanism of action of metformin remains muddled, the compound is still highly relevant for treating metabolic disorders such as T2D, which is likely linked to some interaction with an AMPK-dependent pathway.

\section{SIRT1: relaying mitochondrial redox states to metabolic improvements}

Cellular energetic state is highly associated with its oxidation-reduction (redox) state through the coupling of multiple redox nodes with mitochondrial energy metabolism. One of the key redox nodes is that of $\mathrm{NAD}^{+} / \mathrm{NADH}$, which are critical cofactors that transport electrons during mitochondrial oxidative phosphorylation and function as coenzymes in key metabolic reactions. $\mathrm{NAD}^{+}$has also been proposed to function as a cofactor for the deacetylase sirtuin 1 (SIRT1), which deacetylates and activates PGC1a, promoting mitochondrial biogenesis and

Published by Bioscientifica Ltd. 
energy metabolism in a way similar to exercise (Rodgers et al. 2005). Moreover, AMPK activation elevates the intracellular $\mathrm{NAD}^{+} / \mathrm{NADH}$ ratio and induces the activity of SIRT1 to activate PGC1a, which mediates the energetic functions of AMPK on top of its direct phosphorylation of PGC1a (Canto et al. 2009). Accordingly, drugs that impact the $\mathrm{NAD}^{+} / \mathrm{NADH}$ ratio or target SIRT1 directly have the potential to create exercise-like effects. Recent studies have explored these strategies, using compounds in this manner to increase oxidative metabolism and combat diet-induced obesity in mice. For example, supplementing mice with the $\mathrm{NAD}^{+}$precursor nicotinamide riboside increased intracellular $\mathrm{NAD}^{+}$levels and enhanced mitochondrial function in skeletal muscle and BAT, comprehensively resulting in improved exercise performance (Canto et al. 2012). Similarly, inhibition of the NAD+-consuming DNA repair enzyme poly (ADP-ribose) polymerase 1 (PARP1) conferred resistance to diet-induced metabolic defects through improvements in mitochondrial function and oxidative metabolism in skeletal muscle (Pirinen et al. 2014). Interestingly, genetic deletion of PARP1 or treatment with PARP inhibitors was able to correct the phenotype of mice with dysfunctional synthesis of cytochrome c, a model of mitochondrial disease (Cerutti et al. 2014). Analogously, the administration of nicotinamide riboside to the Twinkle mitochondrial DNA deletor mouse model of mitochondrial disease increased mitochondrial biogenesis in skeletal muscle and blunted the progression of mitochondrial myopathy (Khan et al. 2014). Collectively, compounds that can be used to modulate the cellular redox state by increasing the $\mathrm{NAD}^{+} / \mathrm{NADH}$ ratio can create an exercise-like, PGC1a-dependent induction of mitochondrial and metabolic fitness, which might be useful for combating obesity and T2D.

How else might the SIRT1-PGC1a pathway be exploited to create exercise-like effects? Resveratrol, a naturally occurring polyphenol produced by grapes, is a well-established activator of SIRT1 that can promote mitochondrial function in muscle, increase exercise endurance, and is also linked to longevity (Lagouge et al. 2006). Subsequently, resveratrol has been proposed to combat diseases ranging from cardiac dysfunction to cancer through activation of SIRT1, although its exact mechanism of action is not known (Baur \& Sinclair 2006). Does resveratrol have potential to be used as an exercise mimetic to efficaciously treat diabetes? Resveratrol has undergone a few recent clinical trials to address this question. One trial revealed that administering resveratrol to 10 obese type 2 diabetic males induced the expression of both AMPK and SIRT1 in skeletal muscle, coupled with an increase in resting metabolic rate (Goh et al. 2014). Another trial demonstrated that after 6 months of resveratrol treatment, patients receiving the compound had approximately 10\% higher levels of circulating adiponectin, coupled with reduced expression of inflammatory markers (Tome-Carneiro et al. 2013).

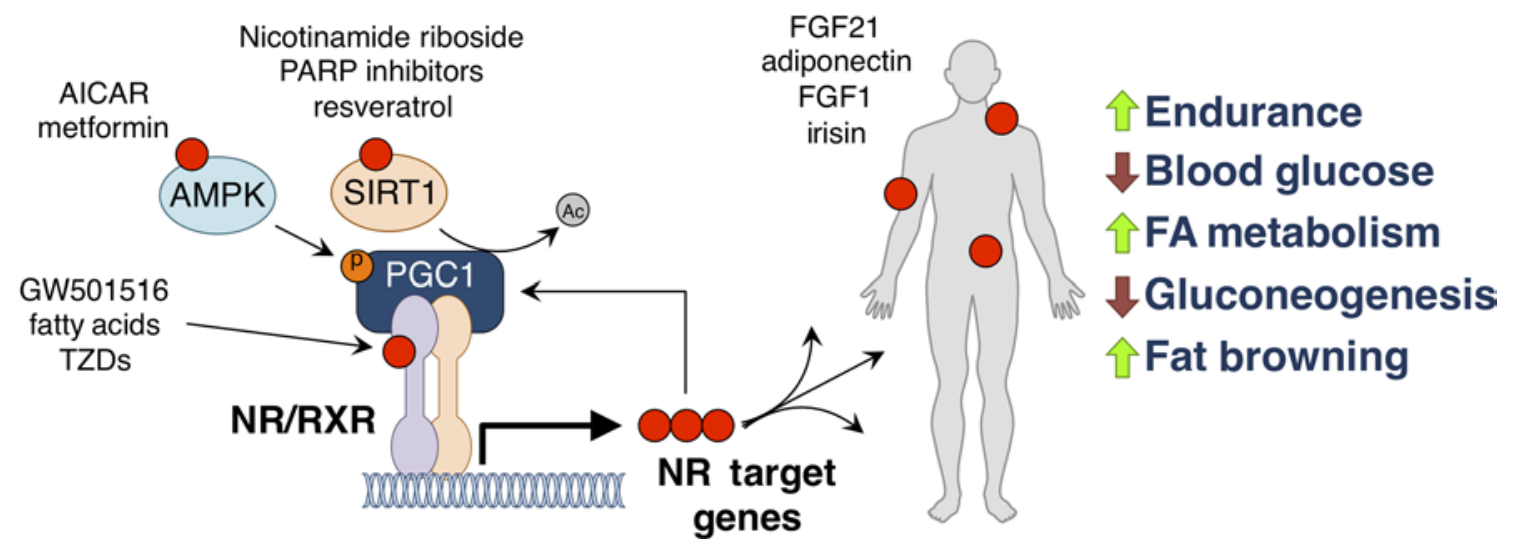

Figure 1

Unified pathways for exercise mimetics. Compounds, either endogenous or synthetic, that can recapitulate the benefits of exercise (red dots) interact with several different parts of a unified nuclear receptor/cofactor transcriptional complex that promotes the expression of genes that maintain metabolic homeostasis. Direct ligands for nuclear receptors (GW501516, fatty acids, and TZDs), activators of the nuclear receptor cofactor PGC1 $\alpha$ AMPK and SIRT1 (AICAR and metformin, and nicotinamide riboside, PARP inhibitors, and resveratrol, respectively), promote the expression of nuclear receptor target genes (FGF21, adiponectin, FGF1, and irisin), which can be secreted to function as endocrine hormones with peripheral effects. Comprehensively, these exercise mimetics can promote endurance in skeletal muscle, lower blood glucose levels, increase fatty acid metabolism, suppress hepatic gluconeogenesis, and cause browning of white fat into beige fat. 
These results suggest that resveratrol treatment might exert beneficial effects on white adipose tissue, potentially mediated through PPAR $\gamma$. Unfortunately, another recent clinical trial administering high doses of resveratrol to 24 obese male subjects for 4 weeks did not show any improvements in insulin sensitivity, glucose homeostasis, or oxidative metabolism (Poulsen et al. 2013). Resveratrol treatment also appeared to suppress exercise-dependent improvements in aerobic respiration in a trial of 27 inactive aged men (Gliemann et al. 2013). Although conflicting clinical evidence exists as to the efficacy of resveratrol to treat diabetes, the compound unquestionably highlights the promise of SIRT1 as a putative antidiabetic target.

\section{Conclusions and perspectives}

The push to develop novel drugs to treat diabetes has never been stronger in the metabolism field, and AMPK/nuclear receptor-regulated pathways continue to remain in the limelight with regard to artificially recapitulating the benefits of exercise. The specific molecular mechanisms dictating how these exercise mimetics work are just beginning to emerge, despite many of these compounds being used to combat diabetes for more than a decade (Fig. 1). Future studies aimed at fleshing out a concrete link between exercise, AMPK, and nuclear receptors, and improvements in metabolic homeostasis will facilitate the development of new exercise mimetics with improved tissue specificity, increased stability, and minimal side effects. Given the amount of recent findings that critically advance our understanding of these drugs, we believe that an exercise mimetic capable of efficaciously treating T2D should be in our near future.

\section{Declaration of interest}

The authors declare that there is no conflict of interest that could be perceived as prejudicing the impartiality of this review.

\section{Funding}

M E is an Investigator of the Howard Hughes Medical Institute at the Salk Institute and March of Dimes Chair in Molecular and Developmental Biology. This work was supported by U.S. National Institutes of Health grants (DK057978, DK090962, HL088093, HL105278, CA014195 and ES010337), the Glenn Foundation for Medical Research, the Leona M. and Harry B. Helmsley Charitable Trust (\#2012-PG-MED002), Ipsen/Biomeasure, and the Ellison Medical Foundation.

\section{Acknowledgments}

The authors thank L Ong and C Brondos for administrative assistance.

\section{References}

Adams AC, Halstead CA, Hansen BC, Irizarry AR, Martin JA, Myers SR, Reynolds VL, Smith HW, Wroblewski VJ \& Kharitonenkov A 2013 LY2405319, an engineered FGF21 variant, improves the metabolic status of diabetic monkeys. PLoS ONE 8 e65763. (doi:10.1371/ journal.pone.0065763)

Andrzejewski S, Gravel SP, Pollak M \& St-Pierre J 2014 Metformin directly acts on mitochondria to alter cellular bioenergetics. Cancer \& Metabolism 2 12. (doi:10.1186/2049-3002-2-12)

Baar K, Wende AR, Jones TE, Marison M, Nolte LA, Chen M, Kelly DP \& Holloszy JO 2002 Adaptations of skeletal muscle to rapid increase in the transcriptional coactivator PGC-1. FASEB Journal 16 1879-1886. (doi:10.1096/fj.02-0367com)

Barish GD, Narkar VA \& Evans RM 2006 PPAR delta: a dagger in the heart of the metabolic syndrome. Journal of Clinical Investigation 116 590-597. (doi:10.1172/JCI27955)

Baron AD, Brechtel G, Wallace P \& Edelman SV 1988 Rates and tissue sites of non-insulin- and insulin-mediated glucose uptake in humans. American Journal of Physiology 255 E769-E774.

Baur JA \& Sinclair DA 2006 Therapeutic potential of resveratrol: the in vivo evidence. Nature Reviews. Drug Discovery 5 493-506. (doi:10.1038/nrd2060)

Berger JP, Akiyama TE \& Meinke PT 2005 PPARs: therapeutic targets for metabolic disease. Trends in Pharmacological Sciences 26 244-251. (doi:10.1016/j.tips.2005.03.003)

Boden G \& Shulman GI 2002 Free fatty acids in obesity and type 2 diabetes: defining their role in the development of insulin resistance and beta-cell dysfunction. European Journal of Clinical Investigation 32 (Supplement 3) 14-23. (doi:10.1046/j.1365-2362.32.s3.3.x)

Bookout AL, de Groot MH, Owen BM, Lee S, Gautron L, Lawrence HL, Ding X, Elmquist JK, Takahashi JS, Mangelsdorf DJ, et al. 2013 FGF21 regulates metabolism and circadian behavior by acting on the nervous system. Nature Medicine 19 1147-1152. (doi:10.1038/ $\mathrm{nm} .3249)$

Bostrom P, Wu J, Jedrychowski MP, Korde A, Ye L, Lo JC, Rasbach KA, Bostrom EA, Choi JH, Long JZ et al. 2012 A PGC1-alphadependent myokine that drives brown-fat-like development of white fat and thermogenesis. Nature 481 463-468. (doi:10.1038/ nature10777)

Butcher LR, Thomas A, Backx K, Roberts A, Webb R \& Morris K 2008 Low-intensity exercise exerts beneficial effects on plasma lipids via PPARgamma. Medicine and Science in Sports and Exercise 401263 1270. (doi:10.1249/MSS.0b013e31816c091d)

Cannon B \& Nedergaard J 2004 Brown adipose function and physiological significance. Physiological Reviews 84 277-359. (doi:10.1152/physrev.00015.2003)

Canto C \& Auwerx J 2009 PGC-1alpha, SIRT1 and AMPK, an energy sensing network that controls energy expenditure. Current Opinion in Lipidology 20 98-105. (doi:10.1097/MOL.0b013e328328d0a4)

Canto C, Gerhart-Hines Z, Feige JN, Lagouge M, Noriega L, Milne JC, Elliott PJ, Puigserver P \& Auwerx J 2009 AMPK regulates energy expenditure by modulating NAD+ metabolism and SIRT1 activity. Nature 458 1056-1060. (doi:10.1038/nature07813)

Canto C, Houtkooper RH, Pirinen E, Youn DY, Oosterveer MH, Cen Y, Fernandez-Marcos PJ, Yamamoto H, Andreux PA, Cettour-Rose P, et al. 2012 The $\mathrm{NAD}(+)$ precursor nicotinamide riboside enhances oxidative metabolism and protects against high-fat diet-induced obesity. Cell Metabolism 15 838-847. (doi:10.1016/j. cmet.2012.04.022)

Cerutti R, Pirinen E, Lamperti C, Marchet S, Sauve AA, Li W, Leoni V, Schon EA, Dantzer F, Auwerx J, et al. 2014 NAD(+)-dependent activation of Sirt 1 corrects the phenotype in a mouse model of mitochondrial disease. Cell Metabolism 19 1042-1049. (doi:10.1016/j. cmet.2014.04.001) http://jme.endocrinology-journals.org

DOI: 10.1530/JME-16-0073
() 2016 Society for Endocrinology Printed in Great Britain 
Choi JH, Banks AS, Estall JL, Kajimura S, Bostrom P, Laznik D, Ruas JL, Chalmers MJ, Kamenecka TM, Bluher M, et al. 2010 Anti-diabetic drugs inhibit obesity-linked phosphorylation of PPARgamma by Cdk5. Nature 466 451-456. (doi:10.1038/nature09291)

Choi JH, Choi SS, Kim ES, Jedrychowski MP, Yang YR, Jang HJ, Suh PG, Banks AS, Gygi SP \& Spiegelman BM 2014a Thrap3 docks on phosphoserine 273 of PPARgamma and controls diabetic gene programming. Genes \& Development 28 2361-2369. (doi:10.1101/ gad.249367.114)

Choi SS, Kim ES, Koh M, Lee SJ, Lim D, Yang YR, Jang HJ, Seo KA, Min SH, Lee IH, et al. 2014b A novel non-agonist peroxisome proliferator-activated receptor gamma (PPARgamma) ligand UHC1 blocks PPARgamma phosphorylation by cyclin-dependent kinase 5 (CDK5) and improves insulin sensitivity. Journal of Biological Chemistry 289 26618-26629. (doi:10.1074/jbc.M114.566794)

Contreras AV, Torres N \& Tovar AR 2013 PPAR-alpha as a key nutritional and environmental sensor for metabolic adaptation. Advances in Nutrition 4 439-452. (doi:10.3945/an.113.003798)

Crujeiras AB, Pardo M \& Casanueva FF 2014 Irisin: 'fat' or artefact. Clinical Endocrinology 82 467-474. (doi:10.1111/cen.12627)

Cuevas-Ramos D, Almeda-Valdes P, Meza-Arana CE, Brito-Cordova G, Gomez-Perez FJ, Mehta R, Oseguera-Moguel J \& Aguilar-Salinas CA 2012 Exercise increases serum fibroblast growth factor 21 (FGF21) levels. PLOS ONE 7 e38022. (doi:10.1371/journal.pone.0038022)

Dressel U, Allen TL, Pippal JB, Rohde PR, Lau P \& Muscat GE 2003 The peroxisome proliferator-activated receptor beta/delta agonist, GW501516, regulates the expression of genes involved in lipid catabolism and energy uncoupling in skeletal muscle cells. Molecular Endocrinology 17 2477-2493. (doi:10.1210/me.2003-0151)

Dreyer C, Keller H, Mahfoudi A, Laudet V, Krey G \& Wahli W 1993 Positive regulation of the peroxisomal beta-oxidation pathway by fatty acids through activation of peroxisome proliferator-activated receptors (PPAR). Biology of the Cell 77 67-76. (doi:10.1016/S02484900(05)80176-5)

Elsen M, Raschke S \& Eckel J 2014 Browning of white does irisin play a role in humans? Journal of Endocrinology 222 R25-R38. (doi:10.1530/ JOE-14-0189)

Fan W, Atkins AR, Yu RT, Downes M \& Evans RM 2013 Road to exercise mimetics: targeting nuclear receptors in skeletal muscle. Journal of Molecular Endocrinology 51 T87-T100. (doi:10.1530/JME-13-0258)

Finck BN \& Kelly DP 2006 PGC-1 coactivators: inducible regulators of energy metabolism in health and disease. Journal of Clinical Investigation 116 615-622. (doi:10.1172/JCI27794)

Foretz M, Hebrard S, Leclerc J, Zarrinpashneh E, Soty M, Mithieux G, Sakamoto K, Andreelli F \& Viollet B 2010 Metformin inhibits hepatic gluconeogenesis in mice independently of the LKB1/AMPK pathway via a decrease in hepatic energy state. Journal of Clinical Investigation 120 2355-2369. (doi:10.1172/JCI40671)

Gaich G, Chien JY, Fu H, Glass LC, Deeg MA, Holland WL, Kharitonenkov A, Bumol T, Schilske HK \& Moller DE 2013 The effects of LY2405319, an FGF21 analog, in obese human subjects with type 2 diabetes. Cell Metabolism 18 333-340. (doi:10.1016/j. cmet.2013.08.005)

Gliemann L, Schmidt JF, Olesen J, Bienso RS, Peronard SL, Grandjean SU, Mortensen SP, Nyberg M, Bangsbo J, Pilegaard H, et al. 2013 Resveratrol blunts the positive effects of exercise training on cardiovascular health in aged men. Journal of Physiology $\mathbf{5 9 1}$ 5047-5059. (doi:10.1113/jphysiol.2013.258061)

Goh KP, Lee HY, Lau DP, Supaat W, Chan YH \& Koh AF 2014 Effects of resveratrol in patients with type 2 diabetes mellitus on skeletal muscle SIRT1 expression and energy expenditure. International Journal of Sport Nutrition and Exercise Metabolism 24 2-13. (doi:10.1123/ijsnem.2013-0045)

Gwinn DM, Shackelford DB, Egan DF, Mihaylova MM, Mery A, Vasquez DS, Turk BE \& Shaw RJ 2008 AMPK phosphorylation of raptor mediates a metabolic checkpoint. Molecular Cell 30 214-226. (doi:10.1016/j.molcel.2008.03.003)

Hardie DG 2011 Sensing of energy and nutrients by AMP-activated protein kinase. American Journal of Clinical Nutrition 93 891S-896S. (doi:10.3945/ajcn.110.001925)

Harms M \& Seale P 2013 Brown and beige fat: development, function and therapeutic potential. Nature Medicine 19 1252-1263. (doi:10.1038/nm.3361)

Holland WL, Adams AC, Brozinick JT, Bui HH, Miyauchi Y, Kusminski CM, Bauer SM, Wade M, Singhal E, Cheng CC, et al. 2013 An FGF21-adiponectin-ceramide axis controls energy expenditure and insulin action in mice. Cell Metabolism 17 790-797. (doi:10.1016/j.cmet.2013.03.019)

Inagaki T, Dutchak P, Zhao G, Ding X, Gautron L, Parameswara V, Li Y, Goetz R, Mohammadi M, Esser V, et al. 2007 Endocrine regulation of the fasting response by PPARalpha-mediated induction of fibroblast growth factor 21. Cell Metabolism 5 415-425. (doi:10.1016/j. cmet.2007.05.003)

Jager S, Handschin C, St-Pierre J \& Spiegelman BM 2007 AMP-activated protein kinase (AMPK) action in skeletal muscle via direct phosphorylation of PGC-1alpha. PNAS 104 12017-12022. (doi:10.1073/pnas.0705070104)

Jonker JW, Suh JM, Atkins AR, Ahmadian M, Li P, Whyte J, He M, Juguilon H, Yin YQ, Phillips CT, et al. 2012 A PPARgamma-FGF1 axis is required for adaptive adipose remodelling and metabolic homeostasis. Nature 485 391-394. (doi:10.1038/nature10998)

Kersten S, Seydoux J, Peters JM, Gonzalez FJ, Desvergne B \& Wahli W 1999 Peroxisome proliferator-activated receptor alpha mediates the adaptive response to fasting. Journal of Clinical Investigation $\mathbf{1 0 3}$ 1489-1498. (doi:10.1172/JCI6223)

Khan NA, Auranen M, Paetau I, Pirinen E, Euro L, Forsstrom S, Pasila L, Velagapudi V, Carroll CJ, Auwerx J, et al. 2014 Effective treatment of mitochondrial myopathy by nicotinamide riboside, a vitamin B3. EMBO Molecular Medicine 6 721-731. (doi:10.1002/ emmm.201403943)

Kharitonenkov A \& Larsen P 2011 FGF21 reloaded: challenges of a rapidly growing field. Trends in Endocrinology \& Metabolism 22 81-86. (doi:10.1016/j.tem.2010.11.003)

Knowler WC, Barrett-Connor E, Fowler SE, Hamman RF, Lachin JM, Walker EA, Nathan DM \& Diabetes Prevention Program Research Group 2002 Reduction in the incidence of type 2 diabetes with lifestyle intervention or metformin. New England Journal of Medicine 346 393-403. (doi:10.1056/nejmoa012512)

Kostadinova R, Montagner A, Gouranton E, Fleury S, Guillou H, Dombrowicz D, Desreumaux P \& Wahli W 2012 GW501516 activated PPARbeta/delta promotes liver fibrosis via p38-JNK MAPKinduced hepatic stellate cell proliferation. Cell \& Bioscience 234. (doi:10.1186/2045-3701-2-34)

Lagouge M, Argmann C, Gerhart-Hines Z, Meziane H, Lerin C, Daussin F, Messadeq N, Milne J, Lambert P, Elliott P, et al. 2006 Resveratrol improves mitochondrial function and protects against metabolic disease by activating SIRT1 and PGC-1alpha. Cell $\mathbf{1 2 7}$ 1109-1122. (doi:10.1016/j.cell.2006.11.013)

Lee P, Linderman JD, Smith S, Brychta RJ, Wang J, Idelson C, Perron RM, Werner CD, Phan GQ, Kammula US, et al. 2014 Irisin and FGF21 are cold-induced endocrine activators of brown fat function in humans. Cell Metabolism 19 302-309. (doi:10.1016/j. cmet.2013.12.017)

Lehrke M \& Lazar MA 2005 The many faces of PPARgamma. Cell 123 993-999. (doi:10.1016/j.cell.2005.11.026)

Lien F, Berthier A, Bouchaert E, Gheeraert C, Alexandre J, Porez G, Prawitt J, Dehondt H, Ploton M, Colin S, et al. 2014 Metformin interferes with bile acid homeostasis through AMPK-FXR crosstalk. Journal of Clinical Investigation 124 1037-1051. (doi:10.1172/ JCI68815) http://jme.endocrinology-journals.org

DOI: 10.1530/JME-16-0073 (c) 2016 Society for Endocrinology Printed in Great Britain
Published by Bioscientifica Ltd 
Lin J, Handschin C \& Spiegelman BM 2005 Metabolic control through the PGC-1 family of transcription coactivators. Cell Metabolism 1 361-370. (doi:10.1016/j.cmet.2005.05.004)

Lin Z, Tian H, Lam KS, Lin S, Hoo RC, Konishi M, Itoh N, Wang Y, Bornstein SR, Xu A, et al. 2013 Adiponectin mediates the metabolic effects of FGF21 on glucose homeostasis and insulin sensitivity in mice. Cell Metabolism 17 779-789. (doi:10.1016/j.cmet.2013.04.005)

Liu W, Zhai X, Li H \& Ji L 2014 Depression-like behaviors in mice subjected to co-treatment of high-fat diet and corticosterone are ameliorated by AICAR and exercise. Journal of Affective Disorders $\mathbf{1 5 6}$ 171-177. (doi:10.1016/j.jad.2013.11.025)

Luengo A, Sullivan LB \& Heiden MG 2014 Understanding the complexI-ty of metformin action: limiting mitochondrial respiration to improve cancer therapy. BMC Biology 12 82. (doi:10.1186/s12915014-0082-4)

Lundasen T, Hunt MC, Nilsson LM, Sanyal S, Angelin B, Alexson SE \& Rudling M 2007 PPARalpha is a key regulator of hepatic FGF21. Biochemical and Biophysical Research Communications 360 437-440. (doi:10.1016/j.bbrc.2007.06.068)

Madiraju AK, Erion DM, Rahimi Y, Zhang XM, Braddock DT, Albright RA, Prigaro BJ, Wood JL, Bhanot S, MacDonald MJ, et al. 2014 Metformin suppresses gluconeogenesis by inhibiting mitochondrial glycerophosphate dehydrogenase. Nature $\mathbf{5 1 0}$ 542-546. (doi:10.1038/nature13270)

Magnusson I, Rothman DL, Katz LD, Shulman RG \& Shulman GI 1992 Increased rate of gluconeogenesis in type II diabetes mellitus. A 13C nuclear magnetic resonance study. Journal of Clinical Investigation $\mathbf{9 0}$ 1323-1327. (doi:10.1172/JCI115997)

Mashili FL, Austin RL, Deshmukh AS, Fritz T, Caidahl K, Bergdahl K, Zierath JR, Chibalin AV, Moller DE, Kharitonenkov A, et al. 2011 Direct effects of FGF21 on glucose uptake in human skeletal implications for type 2 diabetes and obesity. Diabetes/Metabolism Research and Reviews 27 286-297. (doi:10.1002/dmrr.1177)

Mosti MP, Stunes AK, Ericsson M, Pullisaar H, Reseland JE, Shabestari M, Eriksen EF \& Syversen U 2014 Effects of the peroxisome proliferatoractivated receptor (PPAR)-delta agonist GW501516 on bone and muscle in ovariectomized rats. Endocrinology 155 2178-2189. (doi:10.1210/en.2013-1166)

Musi N \& Goodyear LJ 2002 Targeting the AMP-activated protein kinase for the treatment of type 2 diabetes. Current Drug Targets: Immune, Endocrine \& Metabolic Disorders 2 119-127. (doi:10.2174/1568008023340730)

Narkar VA, Downes M, Yu RT, Embler E, Wang YX, Banayo E, Mihaylova MM, Nelson MC, Zou Y, Juguilon H, et al. 2008 AMPK and PPARdelta agonists are exercise mimetics. Cell 134 405-415. (doi:10.1016/j.cell.2008.06.051)

Oliver WR Jr, Shenk JL, Snaith MR, Russell CS, Plunket KD, Bodkin NL, Lewis MC, Winegar DA, Sznaidman ML, Lambert MH, et al. 2001 A selective peroxisome proliferator-activated receptor delta agonist promotes reverse cholesterol transport. PNAS 98 5306-5311. (doi:10.1073/pnas.091021198)

Olson EJ, Pearce GL, Jones NP \& Sprecher DL 2012 Lipid effects of peroxisome proliferator-activated receptor-delta agonist GW501516 in subjects with low high-density lipoprotein cholesterol: characteristics of metabolic syndrome. Arteriosclerosis, Thrombosis, and Vascular Biology 32 2289-2294. (doi:10.1161/ATVBAHA.112.247890)

Ooi EM, Watts GF, Sprecher DL, Chan DC \& Barrett PH 2011 Mechanism of action of a peroxisome proliferator-activated receptor (PPAR)-delta agonist on lipoprotein metabolism in dyslipidemic subjects with central obesity. Journal of Clinical Endocrinology and Metabolism 96 E1568-E1576. (doi:10.1210/jc.2011-1131)

Pirinen E, Canto C, Jo YS, Morato L, Zhang H, Menzies KJ, Williams EG, Mouchiroud L, Moullan N, Hagberg C, et al. 2014 Pharmacological Inhibition of poly(ADP-ribose) polymerases improves fitness and mitochondrial function in skeletal muscle. Cell Metabolism 19 1034-1041. (doi:10.1016/j.cmet.2014.04.002)
Potthoff MJ, Inagaki T, Satapati S, Ding X, He T, Goetz R, Mohammadi M, Finck BN, Mangelsdorf DJ, Kliewer SA, et al. 2009 FGF21 induces PGC-1alpha and regulates carbohydrate and fatty acid metabolism during the adaptive starvation response. PNAS $\mathbf{1 0 6}$ 10853-10858. (doi:10.1073/pnas.0904187106)

Poulsen MM, Vestergaard PF, Clasen BF, Radko Y, Christensen LP, Stodkilde-Jorgensen H, Moller N, Jessen N, Pedersen SB \& Jorgensen JO 2013 High-dose resveratrol supplementation in obese men: an investigator-initiated, randomized, placebo-controlled clinical trial of substrate metabolism, insulin sensitivity, and body composition. Diabetes 62 1186-1195. (doi:10.2337/db12-0975)

Qiang L, Wang L, Kon N, Zhao W, Lee S, Zhang Y, Rosenbaum M, Zhao Y, Gu W, Farmer SR, et al. 2012 Brown remodeling of white adipose tissue by SirT1-dependent deacetylation of Ppargamma. Cell 150 620-632. (doi:10.1016/j.cell.2012.06.027)

Qiu Y, Nguyen KD, Odegaard JI, Cui X, Tian X, Locksley RM, Palmiter RD \& Chawla A 2014 Eosinophils and type 2 cytokine signaling in macrophages orchestrate development of functional beige fat. Cell 157 1292-1308. (doi:10.1016/j.cell.2014.03.066)

Rodgers JT, Lerin C, Haas W, Gygi SP, Spiegelman BM \& Puigserver P 2005 Nutrient control of glucose homeostasis through a complex of PGC-1alpha and SIRT1. Nature 434 113-118. (doi:10.1038/ nature03354)

Russell RR3rd, Bergeron R, Shulman GI \& Young LH 1999 Translocation of myocardial GLUT-4 and increased glucose uptake through activation of AMPK by AICAR. American Journal of Physiology 277 H643-H649.

Schoonjans K, Staels B \& Auwerx J 1996 Role of the peroxisome proliferator-activated receptor (PPAR) in mediating the effects of fibrates and fatty acids on gene expression. Journal of Lipid Research 37 907-925.

Shaw RJ, Lamia KA, Vasquez D, Koo SH, Bardeesy N, Depinho RA, Montminy M \& Cantley LC 2005 The kinase LKB1 mediates glucose homeostasis in liver and therapeutic effects of metformin. Science 310 1642-1646. (doi:10.1126/science.1120781)

Shin JA, Lee JH, Lim SY, Ha HS, Kwon HS, Park YM, Lee WC, Kang MI, Yim HW, Yoon KH, et al. 2013 Metabolic syndrome as a predictor of type 2 diabetes, and its clinical interpretations and usefulness. Journal of Diabetes Investigation 4 334-343. (doi:10.1111/jdi.12075)

Spiegelman BM 1998 PPAR-gamma: adipogenic regulator and thiazolidinedione receptor. Diabetes 47 507-514. (doi:10.2337/ diabetes.47.4.507)

Suh JM, Jonker JW, Ahmadian M, Goetz R, Lackey D, Osborn O, Huang Z, Liu W, Yoshihara E, van Dijk TH, et al. 2014 Endocrinization of FGF1 produces a neomorphic and potent insulin sensitizer. Nature 513 436-439. (doi:10.1038/nature13540)

Sullivan JE, Brocklehurst KJ, Marley AE, Carey F, Carling D \& Beri RK 1994 Inhibition of lipolysis and lipogenesis in isolated rat adipocytes with AICAR, a cell-permeable activator of AMP-activated protein kinase. FEBS Letters 353 33-36. (doi:10.1016/0014-5793(94)01006-4)

Thevis M, Beuck S, Thomas A, Kortner B, Kohler M, Rodchenkov G \& Schanzer W 2009 Doping control analysis of emerging drugs in human plasma - identification of GW501516, S-107, JTV-519, and S-40503. Rapid Communications in Mass Spectrometry 23 1139-1146. (doi:10.1002/rcm.3987)

Tome-Carneiro J, Gonzalvez M, Larrosa M, Yanez-Gascon MJ, GarciaAlmagro FJ, Ruiz-Ros JA, Tomas-Barberan FA, Garcia-Conesa MT \& Espin JC 2013 Grape resveratrol increases serum adiponectin and downregulates inflammatory genes in peripheral blood mononuclear a triple-blind, placebo-controlled, one-year clinical trial in patients with stable coronary artery disease. Cardiovascular Drugs and Therapy 27 37-48. (doi:10.1007/s10557-012-6427-8)

Vidal-Puig A, Jimenez-Linan M, Lowell BB, Hamann A, Hu E, Spiegelman B, Flier JS \& Moller DE 1996 Regulation of PPAR gamma gene expression by nutrition and obesity in rodents. Journal of Clinical Investigation 97 2553-2561. (doi:10.1172/JCI118703) 
Wang YX, Lee CH, Tiep S, Yu RT, Ham J, Kang H \& Evans RM 2003 Peroxisome-proliferator-activated receptor delta activates fat metabolism to prevent obesity. Cell 113 159-170. (doi:10.1016/ S0092-8674(03)00269-1)

Wang D, Wang H, Guo Y, Ning W, Katkuri S, Wahli W, Desvergne B, Dey SK \& DuBois RN 2006 Crosstalk between peroxisome proliferator-activated receptor delta and VEGF stimulates cancer progression. PNAS 103 19069-19074. (doi:10.1073/ pnas.0607948103)

Wang X, Sng MK, Foo S, Chong HC, Lee WL, Tang MB, Ng KW, Luo B, Choong C, Wong MT, et al. 2015 Early controlled release of peroxisome proliferator-activated receptor beta/delta agonist GW501516 improves diabetic wound healing through redox modulation of wound microenvironment. Journal of Controlled Release 197 138-147. (doi:10.1016/j.jconrel.2014.11.001)

Warburton DE, Nicol CW \& Bredin SS 2006 Health benefits of physical the evidence. Canadian Medical Association Journal 174 801-809. (doi:10.1503/cmaj.051351)

Wei W, Dutchak PA, Wang X, Ding X, Wang X, Bookout AL, Goetz R, Mohammadi M, Gerard RD, Dechow PC, et al. 2012 Fibroblast growth factor 21 promotes bone loss by potentiating the effects of peroxisome proliferator-activated receptor gamma. PNAS 109 3143-3148. (doi:10.1073/pnas.1200797109)

Wu Z, Puigserver P, Andersson U, Zhang C, Adelmant G, Mootha V, Troy A, Cinti S, Lowell B, Scarpulla RC, et al. 1999 Mechanisms controlling mitochondrial biogenesis and respiration through the thermogenic coactivator PGC-1. Cell 98 115-124. (doi:10.1016/ S0092-8674(00)80611-X)

Wu AL, Kolumam G, Stawicki S, Chen Y, Li J, Zavala-Solorio J, Phamluong K, Feng B, Li L, Marsters S, et al. 2011 Amelioration of type 2 diabetes by antibody-mediated activation of fibroblast growth factor receptor 1. Science Translational Medicine 3 113ra126. (doi:10.1126/scitranslmed.3002669)

Yamauchi T, Kamon J, Waki H, Terauchi Y, Kubota N, Hara K, Mori Y, Ide T, Murakami K, Tsuboyama-Kasaoka N, et al. 2001 The fatderived hormone adiponectin reverses insulin resistance associated with both lipoatrophy and obesity. Nature Medicine 7 941-946. (doi:10.1038/90984)

Zhang Y, Wang Y, Bao C, Xu Y, Shen H, Chen J, Yan J \& Chen Y $2012 a$ Metformin interacts with AMPK through binding to gamma subunit. Molecular and Cellular Biochemistry 368 69-76. (doi:10.1007/s11010012-1344-5)

Zhang Y, Xie Y, Berglund ED, Coate KC, He TT, Katafuchi T, Xiao G Potthoff MJ, Wei W, Wan Y, et al. 2012b The starvation hormone, fibroblast growth factor-21, extends lifespan in mice. Elife 1 e00065. (doi:10.7554/eLife.00065)

Zhou G, Myers R, Li Y, Chen Y, Shen X, Fenyk-Melody J, Wu M, Ventre J, Doebber T, Fujii N, et al. 2001 Role of AMP-activated protein kinase in mechanism of metformin action. Journal of Clinical Investigation 108 1167-1174. (doi:10.1172/JCI13505)

Received in final form 12 April 2016

Accepted 19 April 2016

Accepted Preprint published online 22 April 2016 (c) 2016 Society for Endocrinology Printed in Great Britain
Published by Bioscientifica Ltd. 